Faculdade de Ciências Econômicas UFRGS

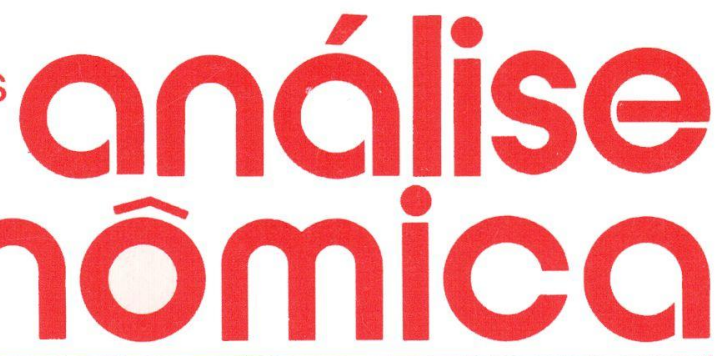

- teoria do balanço de PAGAMENTOS Joáo Luis Tenreiro Barroso

- a IMPORTÂncIa das teorias DE SALÁRIO PARA AS TEORIAS DE INFLAÇÃO Lúcia Maria Góes Moutinho

- os ciclos da economia BRASILEIRA

Vera Beatriz da Silva Oliveira

- SUBSÍDIOS DE PREÇOS AO TRIGO NO BRASIL

Vera Martins da Silva

- A EFICIÊnCIA dA AGRICULtURA GAÚCHA

Juvir Luiz Mattuella

- A economia Regional no BRASIL

Paulo Roberto Haddad

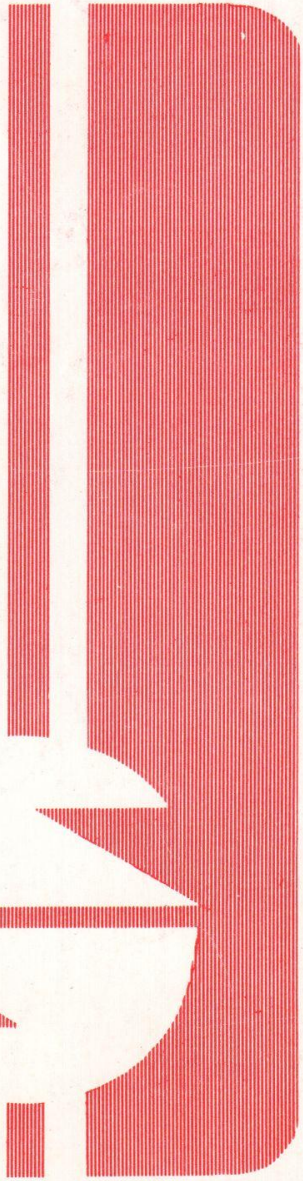


UNIVERSIDADE FEDERAL DO RIO GRANDE DO SUL

Reitor: Prof. Gerhard Jacob

FACULDADE DE CIÊNCIAS ECONÔMICAS

Diretor. Prof. Walter Meucci Nique

CENTRO DE ESTUDOS E PESQUISAS ECONÔMICAS

Diretor: Prof. Reinaldo Ignacio Adams

DEPARTAMENTO DE CIÊNCIAS ECONÔMICAS

Chefe: Profa Oțtlia Beatriz Kroeff Carrion

CURSO DE PÓS-GRADUAÇĀO EM ECONOMIA

Coordenador: Prof. Roberto Camps Moraes

CURSO DE PÓS-GRADUAÇĀO EM ECONOMIA RURAL

Coordenador: Prof. Aray Miguel Feldens

CONSELHO EDITORIAL:

Achyles Barcelos da Costa, Aray Miguel Feldens, Atos Freitas Grawunder, Carlos Augusto Crusius, Ernani Hickmann, João Rogério Sanson, Juvir Luiz Mattuella, Maria Imilda da Costa e Silva, Nali de Jesus de Souza, Nuno Renan Lopes de Figueiredo Pinto, Otília Beatriz Kroeff Carrion, Otto Guilherme Konzen, Paulo Alexandre Spohr, Pedro Cezar Dutra Fonseca, Reinaldo Ignacio Adams, Roberto Camps Moraes, Valter José Stülp, Yeda Rorato Crusius, Edgar Augusto Lanzer (UFSC) e Humberto Vendelino Richeter (UnB)

COMISSĀO EDITORIAL: Atos Freitas Grawunder; Pedro Cezar Dutra Fonseca, Reinaldo Ignacio Adams e Roberto Camps Moraes.

EDITOR: Nali de Jesus de Souza

SECRETARIA: Francisco Carlos Becco dos Santos, Maria Ivone de Mello (normalizaçāo), Vanete Ricacheski (revisão de textos), Wagner Nunes e Zélide Bregaida.

FUNDADOR: Prof. Antônio Carlos Rosa

A Revista ANÁLISE ECONÔMICA publica dois números anuais nos meses de março e novembro. O preço da assinatura, para 1990, é de 7,0 BTNs (o número avulso custa 4 BTNs), a ser pago através de cheque nominal em nome da "Faculdade de Ciências Econômicas/ UFRGS". Aceita-se permuta com revistas congêneres. Aceitam-se, também, livros para elaboração de resenhas ou recensōes.

Toda correspondência, material para publicação, assinaturas e permutas devem ser dirigidos ao seguinte destinatário:

PROF. NALI DE JESUS DE SOUZA

Revista Análise Econômica

Av. João Pessoa, 52 - sala 28

90.040 - PORTO ALEGRE (RS) - BRASIL

Telefone: 25-5844 ramal 34 


\section{SUBSÍDIOS DE PREÇOS À PRODUÇÃO E CONSUMO DE TRIGO NO BRASIL}

Vera Martins da Silva*

\section{A INTERVENÇÃo GOVERNAMENTAL NO MERCADO DE TRIGO}

Duas características básicas tornaram trigo e derivados sujeitos a uma política específica: por um lado, representavam um elevado peso nos orçamentos domésticos dos centros urbanos nas regiōes Sul e Sudeste; por outro lado, a cultura de trigo em grão era associada a elevado risco de produção e comercialização, em função das condições edafo-climáticas e da heterogeneidade no rendimento e qualidade do grāo.

A importância dos derivados de trigo nos orçamentos e sua dificuldade de adaptação incentivaram o governo a desenvolver pesquisa agrícola e estimular a mistura de farinhas. Entretanto, política interna para o setor enfrentaria um adversário pesado a nivel internacional em meados da década de cinqüenta, pois o crescimento dos estoques de trigo no principais produtores externos - EUA e Canadá - gerou uma redução significativa nos preços reais do cereal.

Além disso, a política dos paises exportadores de manutenção de renda do setor agrícola gerava a aquisição e manutenção de elevado nivel de estoques, que somente seriam reduzidos através de programas de ajuda alimentar a países subdesenvolvidos, nomeadamente, a Public Law-480. Através deste programa, foi possivel importar trigo americano com preços extremamente reduzidos e créditos de longo

* Mestranda do IPE/FEA/USP e economista do CEPAM - Fundaçăo Prefelito Faria Lima (SP)

\begin{tabular}{|l|l|l|l|l|}
\hline ANÁLISE ECONÔMICA & ANO 7 & No11 & MARCO/89 & p.91-113 \\
\hline
\end{tabular}


prazo, que tornavam a importação do cereal uma transação vantajosa para a redução do custo de vida nos centros urbanos-industriais, bem como para entrada de divisas estrangeiras de curto prazo, em detrimento da produção doméstica.

O diferencial de preços do trigo, em favor do trigo estrangeiro, associado à obrigatoriedade da moagem de trigo nacional proporcionalmente às cotas de moagem na indústria, gerou uma gama de fraudes envolvendo o trigo nacional, o importado e cotas da indústria: o cereal importado era vendido como doméstico para apropriação do diferencial de preços, a indústria ampliava sua capacidade de moagem de fato, através de subsídios à importação de maquinaria, ou apenas de registro, para ampliar sua disponibilidade de trigo importado.

Para eliminar as fraudes, o governo foi progressivamente aumentando a regulação sobre este mercado. A partir de 1951, ocorre o monopólio da importação pelo Estado; em 1962, o Banco do Brasil passa a adquirir a safra interna do grão, além do aprimoramento do sistema de cotas, prevalecente desde 1951. Em 1967, há a regulação final (atual) do setor, através das provas físicas da moagem e liberação de $40 \%$ do equipamento industrial para fins de distribuição de cotas, face ao elevado grau de aciosidade na indústria.

A ampla regulação do setor permitiu que fosse implementada uma politica de preços com baixa ocorrência de fraudes. Em 1972/73, com o boom nos preços internacionais dos grãos, é introduzido explicitamente o subsídio ao consumo, através do qual o governo revendia o grão aos moinhos por um preço significativamente inferior ao de aquisição. Na ocasião, a alta dos preços internacionais foi considerada passageira e o subsídio visava o isolamento do mercado doméstico em relação ao mercado internacional. Porém, o que se verificou nos anos seguintes foi a volta dos preços reais do trigo no mercado externo a seu nível pré-choque de preços e a manutenção da política interna de subsídios.

Dentro dessa perspectiva é que se coloca a questão dos subsídios de preços para o setor, basicamente através da análise dos preços para o produtor e consumidor, discutida adiante.

\section{CARACTERIZAÇÃo TEÓRICA dOS DIVERSOS GRUPOS ENVOLVIDOS NO MERCADO DE TRIGO BRASILEIRO}

Os produtores do grão doméstico operam numa estrutura concor- 
rencial, i.e., há um grande número de firmas que tomam o preço como dado. Nem mesmo as cooperativas de trigo, incentivadas originariamente pelo Estado, têm sido capazes de determinar o nível de preços do grão: as cooperativas destacam-se, de fato, na comercialização do mesmo, pois é através delas que o Banco do Brasil efetua as compras do cereal. ${ }^{1}$

Com a diversificação de atividades da agricultura sulina, principalmente com a soja nos anos setenta, a comercialização do trigo perdeu sua importância relativa para os produtores e cooperativas que, apesar de continuarem demandando preço e crédito, tiveram maiores oportunidades de rentabilidade em outros produtos. Isso foi possível pela característica técnica das firmas agrícolas, que podem alterar seu mix de produto de acordo com as condições correntes nos mercados de produtos e insumos.

A regulação é uma variável muito mais crucial no que se refere ao setor moageiro, uma vez que há uma grande especificidade técnica de produção, os preços do grão e produtos da moagem, bem como as cotas têm sido determinados pelas agências reguladoras. Essas caracteristicas tornam esse grupo de interesse o mais sensivel a eventuais mudanças na regulação. Neste caso, a diversificação de atividades na mesma base técnica não é possivel, ocorrendo a diversificação em outras áreas, ligadas ao trigo ou não.

De modo geral, a moagem de trigo apresenta características de um oligopólio concentrado, i.e., as firmas operam sob diferentes condiçōes de custos, devido às diferentes combinações no uso dos fatores, bem como por diferenças qualitativas no equipamento utilizado; não há diferenciação do produto, mas ocorre a produção de um mix de produto (farinha especial, farinha comum e farelo), possível de ser produzido por qualquer firma da indústria. ${ }^{2}$

Entre as indústrias consumidoras de farinha e farelo, a indústria de panificação é a mais regulada no que se refere a preços tabelados e qualidade (peso e características). No caso do pão francês e benga-

\footnotetext{
1 Apesar de que sáo os representantes das cooperativas que, tradicionalmente, negociam com o governo o preço de aquisição da safra, percebe-se seu limitado poder de atuação, através do preço de aquisiçáo do cereal fixado pelo governo, que tem ficado abaixo daquele pretendido pelas cooperativas. Já as vantagens de crédito foram fartamente distribufdas pelo setor agrifcola como um todo, de modo que năo se pode correlacioná-las, exclusivamente, com as demandas das cooperativas triticolas.

2 Caracterizaçăo baseada em Labini (1980).
} 
la, que constituem o grosso da produçāo desta indústria, pode-se dizer que se trata de uma estrutura "aparentemente concorrencial". Deve-se enfatizar seu aspecto "aparente", uma vez que num regime de concorrência perfeita, nenhuma firma é capaz de impor seu preço, face ao tamanho reduzido de cada produtor. $O$ preço é tomado do mercado como sinalizador da escassez relativa do produto. Já no caso da indústria de pão francês e bengala, ou seja, no caso das padarias, o preço é estabelecido pelas agências reguladoras, no caso o CIP, a partir de uma regra de mark-up sobre os custos médios de uma amostra de padarias-padrão. Entretanto, representantes do setor sugeriram que, com o nivel de preços estabelecidos ao longo dos anos, houve um incentivo à expansão do número de firmas operando nesta indústria, muitas das quais estariam operando com capacidade ociosa elevada e, portanto, incorrendo em custos mais elevados do que no caso de uma estrutura perfeitamente concorrencial. ${ }^{3}$ Como os custos e preços analisados pelo CIP tendem a se situar acima daqueles que prevaleceriam em concorrência, não se pode relacionar esta indústria com concorrência perfeita, mas com uma estrutura do tipo "concorrência regulada" ou cartelizada pelo Estado.

Nas demais indústrias consumidoras diretas dos produtos da moagem - massas, biscoitos e rações - a política de preços para o setor tem sido muito mais flexível, permitindo uma maior concorrência via preços dos produtos finais, enquanto que a diferenciação de produtos, embora exista, não é a mais relevante forma de concorrência. Trata-se de indústrias em condições de oligopólio competitivo, cujas barreiras à entrada se caracterizam por controle da comercialização e não por vantagens técnicas na produção ou nós produtos. 4

Os consumidores finais do trigo, representados pela maior parte da população brasileira, é o grupo de interesse mais numeroso no mercado de trigo, cujas características estruturais - distribuição de renda e padrão de consumo - o tornam extremamente sensivel a alterações no preço dos derivados de trigo.

3 Informaçăo coletada no Sindicato da Indústria de Panificaçăo de Săo Paulo em 1988.

4 Tavares (1978), p.303-8, indica que a maioria das firmas que operam em condiçбes de oligopólio competitivo se referem a bens de consumo năo-durável. 


\section{O SUBSídIo À PRODUÇÃo E AO CONSUMO ATRAVÉS DA ANÁLISE DE COMÉRCIO INTERNACIONAL}

A política de preços para o trigo, seguida a partir de 1950, apresentou duas partes distintas: o subsídio de preços à produção para incentivar o plantio desta cultura e o subsídio ao consumo. Este último surgiu na década de cinqüenta com o populismo, foi reduzido na década de sessenta e reapareceu explicitamente após o aumento dos preços internacionais do produto em grão em 1973.

O modelo de comércio internacional utilizado na análise assume que o mercado doméstico de trigo em grão apresenta concorrência perfeita - produto homogêneo e oferta caracterizada por firmas (unidades agrícolas) tomadoras de preço. Além disso, neste mercado aberto ao comércio internacional, a atuaçāo governamental gera alteraçōes na quantidade ofertada e demandada do produto devido a subsídios de preços à produção e ao consurno.

Através do diagrama 1 de equilíbrio parcial em comércio internacional, estão representadas as políticas de subsídio à produção e ao consumo. 5

O Diagrama 1 reproduz uma análise de um país pequeno em comércio internacional, permitindo distinguir uma situação de livre-comércio com uma outra de intervenção do governo do país. No primeiro caso, ao preço internacional $P_{w}$, a quantidade produzida internamente é $Q_{s}$ e a quantidade demandada é $Q_{w}$. Neste caso, há um excesso de demanda interna $\left(Q_{w}-Q_{S}\right)$, que é suprida por importação. Agora, supondo que o governo deseje proteger a produção doméstica e aplique uma tarifa sobre o produto importado, de modo que o novo preço de equilíbrio vigente no mercado interno seja $P_{p}$, superior ao preço anteriormente vigente. Nesse nível de preços, a' produção eleva-se para $Q_{p}$ e a diferença entre os preços no mercado interno e externo é a taxa de subsídio de preço à produção doméstica.

5. Este diagrama, apresentado por Corden (1971), foi também utilizado no estudo do caso da polftica trittcola brasileira por Knight (1971), Soares (1980) e Calegar \& Schuh (1986). 


\section{Diagrama 1}

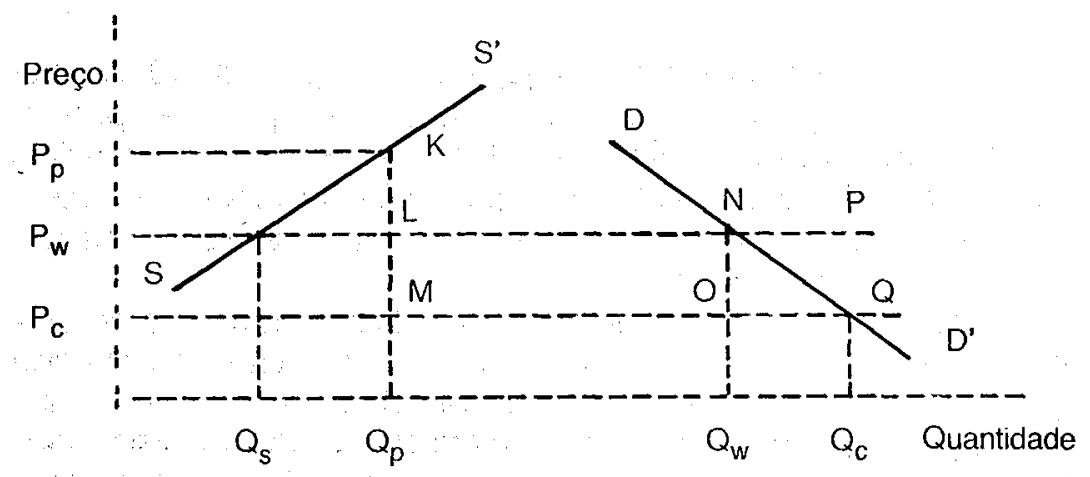

Onde:

$\mathrm{SS}^{\prime} \quad=$ oferta doméstica de trigo em grão

$\mathrm{DD}^{\circ}=$ demanda doméstica de trigo em grão

$\mathrm{P}_{\mathrm{w}} \quad=$ Preço do trigo em grão importado, posto moinho

$\mathrm{P}_{\mathrm{p}} \quad=$ preço do trigo em grão nacional, posto moinho

$P_{C} \quad: \quad=$ preço do trigo em grão vendido aos moinhos

$\mathrm{Q}_{\mathrm{S}} \quad=$ quantidade de trigo em grão ofertada internamente, na ausência dé proteção ao produto doméstico

$\mathrm{Q}_{\mathrm{p}} \quad=$ quantidade de trigo em grão ofertada internamente com proteção ao produto doméstico ${ }^{6}$

$\mathrm{Q}_{\mathrm{w}}=$ quantidade de trigo em grão consumida internamente na ausência de subsídio ao consumo

$\mathrm{Q}_{\mathrm{C}} \quad=$ quantidade de trigo em grão consumida internamente com a presença de subsídio ao consumo

$P_{p} P_{w} K L=$ subsídio à produção nacional

$P_{W} P_{c} P Q=$ subsidio ao consumo

Se, além disso, for instituído um subsídio de preços ao consumo no mercado interno, o preço ao consumidor cai de $P_{w}$ para $P_{C}$, a quan-

6 Assume-se que os estoques domésticos do cereal săo desprezlveis no perlodo relevante de análise. 
tidade demandada aumenta em $\left(Q_{c}-Q_{w}\right)$, sendo a diferença de preços a taxa de subsídio unitário ao consumo. Há, então, proteção ao consumo doméstico.

Apesar de que, no mercado brasileiro de trigo em grão, hă discrepâncias do modelo teórico usual, uma vez que, entre a oferta e a demanda, há o monopólio estatal da comercialização, bem como não há um sistema tarifário sobre o produto importado, mas sim uma situação em que o governo adquire a safra nacional por um preço diferente do preço em vigor no mercado internacional, a construção teórica representada pelo Diagrama 1 reflete bem o caso em análise, sendo a mais apropriada para verificar os impactos das políticas de subsídio de preço sobre produção e consumo domésticos, tomando-se como referencial os preços e quantidades de livre comércio, a partir dos quais se avaliam os subsídios de preço. ${ }^{7}$

Além disso, a existência do monopólio estatal da comercialização implica que é possível ocorrer uma situação de déficit do governo mesmo na ausência de subsídio ao consumo e à produção, bastando para isso que o preço de venda aos moinhos seja inferior ao preço de aquisição do grão. Isto porque, segundo a metodologia aqui utilizada, o subsídio só se define pela discrepância entre preços domésticos e internacionais e não pela intervenção do governo na comercialização.

Os subsídios de preço à produção e ao consumo são benefícios auferidos por dois grupos de interesse - os produtores agrícolas e os consumidores finais, e é tendo em vista averiguar como os benefícios foram distribuidos por esses dois grupos que a estimativa dos subsidios se torna indispensável. 8

Para avaliar o impacto dessas políticas, recorremos à análise da proteção nominal e efetiva, destacadas a seguir.

\subsection{A proteção nominal}

Neste trabalho, estima-se a taxa de subsídio de preços para o período 1965/87, a partir de uma análise de proteção à produção, utilizando-se o indicador "Taxa de Proteção Noninal à Produção" (TPNP):

7 Segundo Corder (1971), p.27, a referência a "livre-comércio" diz respeito à ausência de tarifas e subsidios no pals em análise e năo nos outros países.

8 Observe-se que esta análise pressupర̃e que as indústrias de processamento de grăo săo apenas repassadoras do subsidio ao consumo. 


$$
\text { TPNP }=\left(P_{p}-P_{w}\right) / P_{w} \times 100
$$

Este indicador revela, em termos percentuais, o quanto o preço doméstico do produto está acima do preço de importação, posto moinho, i.e., consideram-se as despesas para colocar o produto nos moinhos:

$$
\begin{aligned}
& P_{p}=\left(P_{f}+M_{m}\right) / E \\
& P_{w}=P_{f o b}+M_{b}
\end{aligned}
$$

\section{Onde:}

$\mathrm{P}_{\mathrm{f}}=$ preço pago ao produtor nacional, em moeda doméstica

$P_{\text {fob }}=$ preço do trigo importado em moeda estrangeira

$\mathrm{E} \quad=$ taxa cambial (Cr\$/US\$)

$M_{m}=$ despesas da fazenda ao moinho

$M_{b}=$ despesas do porto ao moinho

Em relação ao consumo, a taxa de subsídio pode ser avaliada pela "Taxa de Proteção Nominal ao Consumo" (TPNC):

$$
\text { TPNC }=\left(P_{W}-P_{C}\right) / P_{C} \times 100
$$

Um elemento importante, neste tipo de análise, é a taxa cambial adotada para comparação entre os preços domésticos e preços externos, uma vez que o problema da sobrevalorização cambial é acentuado nos paises em desenvolvimento - entre os quais, o Brasil. A taxa cambial, que seria uma aproximação da taxa de livre-comércio, chamaremos de taxa de câmbio social ou de paridade. Neste trabalho, odotou-se uma estimativa da sobrevalorização cambial brasileira entre 1965 e 1987, a partir da paridade do poder de compra da moeda (PPC) em sua versão mais simplificada. ${ }^{9}$

Entretanto, a análise da produção nominal à produção é apenas um indicativo da política seguida para o setor ao longo do período, procurando identificar se houve continuidade no incentivo à produção

9 As estimativas da sobrevalorização cambial brasileira segundo a PPC simples mostraramse bastante próximas das estimativas de outros autores para o perfodo 1971/87. 
doméstica e em que nível. Porém, a literatura sobre políticas protecionistas enfatiza a necessidade de se averiguar a proteção efetiva, que incorpora na análise a proteção aos insumos intermediários, como será visto a seguir.

\subsection{A proteção efetiva}

A proteção efetiva $\left(g_{i}\right)$ procura verificar se, para o caso de produtos supostamente protegıdos através de preços finais, há tarifas, custo de transporte internacional elevado ou produção doméstica ineficiente de insumos, que desprotegem o produto final. Assim, ao invés de comparar preços dos produtos finais, a taxa de proteção efetiva compara a variação entre valor adicionado com tarifas ou subsídios com valor adicionado em livre-comércio. Assim:

$$
\begin{aligned}
g_{i} & =\frac{v_{i}-v_{i}}{v_{i}}= \\
g_{i} & =\frac{\left[\left(1+t_{i}\right)-\operatorname{SUM}\left(1+t_{j}\right) a_{i j}\right] x_{i}}{\left[1-\operatorname{SUM}\left(a_{i j}\right)\right] x_{i}}=\frac{t_{i}-\operatorname{SUM}\left(t_{j} a_{i j}\right)}{1-\operatorname{SUM}\left(a_{i j}\right)}
\end{aligned}
$$

Onde:

$$
\begin{aligned}
& \mathrm{V}_{\mathrm{i}}=\text { valor adicionado com tarifas ou subsídios } \\
& \mathrm{V}_{\mathrm{i}}=\text { valor adicionado em livre-comércio } \\
& \mathrm{t}_{\mathrm{i}}=\text { tarifa sobre produto final } \\
& \mathrm{t}_{\mathrm{j}} \quad=\text { tarifa sobre insumos intermediários } \\
& \mathrm{a}_{\mathrm{ij}}=\text { coeficiente de produção técnica } \\
& \mathrm{X}_{\mathrm{i}}=\text { quantidade produzida do bem } \mathrm{i} \\
& \text { SUM }=\text { somatório }
\end{aligned}
$$

A análise desenvolvida a seguir apresenta os resultados da proteção nominal para o período 1965/87 segundo a taxa de câmbio oficial e social (ou de paridade) e as estimativas de proteção efetiva para 1985, 1986 e 1987, calculadas por Farina et alii (1988). 


\section{EVIDÊNCIAS EMPÍRICAS}

\subsection{Proteção á produção doméstica}

Segundo informações colhidas no CTRIN (Banco do Brasil), em média, ao preço FOB de importação $\left(\mathrm{P}_{\mathrm{fob}}\right)$, devem ser acrescentados $40 \%$ a título de despesas de transporte, despesas portuárias e comissão do banco. ${ }^{10}$ Assim, $M_{b}=40 \%$.

No caso do produto nacional, ao preço pago ao produtor devem ser acrescidos $20 \%$, em média, correspondendo a despesas de transporte e armazenagem. Em relação ao custo financeiro de carregar o estoque de trigo doméstico, assumimos duas situações: entre 1965 e 1981, o custo financeiro foi tomado com $6 \%$ a.a. (remuneração da poupança), pois tratou-se de um perlodo de taxas de juros baixas. A partir de 1982, adotou-se um custo financeiro de $12 \%$ a.a. devido aos problemas financeiros e ao ajuste interno que a economia brasileira enfrentou no período. Assim sendo, $M_{m}=(20 \%+6 \%)$ para 1965/81 e $(2 Q \%+12 \%)$ para $1982 / 87$.

A taxa de proteção nominal, refletindo a discrepância entre o preço prevalecente no mercado doméstico e o preço no mercado internacioanl, posto moinho, pode ser avaliada em termos da taxa cambial oficial e social. Se a taxa cambial adotada for a oficial $\left(E_{0}\right)$, então obteremos a taxa de proteção nominal oficial $\left(\operatorname{TPNP}_{\mathrm{o}}\right)$ e, se for utilizada a taxa cambial social $\left(E_{S}\right)$, teremos a taxa de proteção nominal social ou de paridade $\left(\mathrm{TPNP}_{\mathrm{S}}\right) .{ }^{11}$

Na Tabela 1, apresentam-se os resultados da proteção nominal à produção entre 1965/87. Conforme as estimativas, a proteção nominal à produção de trigo em grão apresentou um comportamento instável ao longo do período analisado, que pode ser visualizado no Gráfico 1.

A proteção nominal foi positiva e declinante entre 1966 e 1973, tanto pela taxa de câmbio oficial como pela paridade. Em 1973, a pro-

10 Cerca de $10 \%$ das despesas com trigo importado referem-se a despesas financeiras de compras efetuadas no exterior no passado. Porém, como geralmente esses contratos de importaçăo gozavam de vários meses de carência, é como se o trigo importado fosse, na realidade, mais barato. Assim, ou se considera o preço do trigo mais barato, no passado, ou se acresce ao trigo importado atualmente as despesas financeiras. Neste caso, optouse pelo segundo método.

11 Na transformação de preços pagos ao produtor em cruzeiros para dólares americanos, foi utilizada a taxa cambial do quarto trimestre do ano $\left(E_{0} I V\right)$, pois o pico da colheita ocorre nesse perlodo. 
teção atingiu seu nivel mais baixo, devido ao boom preços no mercado internacional, para, a seguir, apresentar uma tendência ascendente até 1977. Observa-se que a proteção nominal à produção, medida pela taxa cambial de paridade, foi negativa no período 1972/81, com exceção dos anos de 1977 e 1978. A partir de 1980, houve um incremento à produção nominal do trigo em grão doméstico, tanto em termos da taxa cambial oficial como da paridade. A Tabela 2 fornece a média dos resultados para sub-períodos específicos.

\section{TABELA 1 - TAXA DE PROTEÇÃo NOMINAL À PRODUÇÃO - TPNP; 1965/87 (\%)}

\begin{tabular}{crc}
\hline Ano & $\begin{array}{c}\text { Câmbio } \\
\text { Oficial }\end{array}$ & $\begin{array}{c}\text { Câmbio de } \\
\text { Paridade }\end{array}$ \\
\hline 1965 & 42,75 & 18,27 \\
1966 & 93,96 & 48,21 \\
1967 & 68,05 & 27,24 \\
1968 & 55,41 & 19,48 \\
1969 & 63,43 & 29,47 \\
1970 & 49,82 & 14,75 \\
1971 & 40,37 & 7,25 \\
1972 & 11,42 & $-15,31$ \\
1973 & $-20,52$ & $-39,24$ \\
1974 & $-10,77$ & $-31,27$ \\
1975 & 8,95 & $-14,95$ \\
1976 & 21,80 & $-7,04$ \\
1977 & 72,27 & 30,76 \\
1978 & 49,80 & 13,74 \\
1979 & $-12,21$ & $-30,63$ \\
1980 & $-5,89$ & $-21,85$ \\
1981 & 22,75 & $-2,85$ \\
1982 & 51,41 & 21,15 \\
1983 & 28,03 & 17,72 \\
1984 & 33,56 & 20,24 \\
1985 & 61,89 & 47,65 \\
1986 & 128,32 & 90,86 \\
1987 & 76,44 & 35,18 \\
\hline
\end{tabular}

FONTE: Silva (1989) 
Observa-se que, entre 1965 e 1971, periodo pré-choque de preços internacionais de trigo em grão, a política estabelecia uma proteção nominal à cultura de trigo da ordem de $23 \%$, segundo a taxa de paridade. Entre 1972 e 1974, período do choque dos preços externos, a proteção nominal com câmbio oficial (TPNP ${ }_{\rho}$ ) foi negativa, indicando que os preços estabelecidos para o produtor ficaram aquém do preço no mercado internacional, ou seja, o Governo segurou os preços domésticos, isolando o mercado interno das oscilaçôes do mercado externo. Neste periodo, a TPNP (paridade) alcançou - $29 \%$.

Segundo a tabela 2, a proteção nominal oficial seria de $22 \%$, no período 1975/81, porém, com o efeito da sobrevalorização cambial, houve uma "desproteção" de $5 \%$, valor médio relativamente baixo devido à ocorrência de queda de preços externos em 1976 e 1977.

De 1982 em diante, quando se inicia o ajuste do setor externo, a política se inverte e passa a haver uma proteção nominal positiva, em termos de taxa oficial $(63 \%)$ ou de paridade $(39 \%)$, sendo a taxa de proteção deste último subperíodo superior ao subperíodo inicial (1965/71).

\section{GRÁFICO 1}

\section{PROTEÇÃO NOMINAL À PRODUÇĀO DE TRIGO NO BRASIL $1967-1985$}

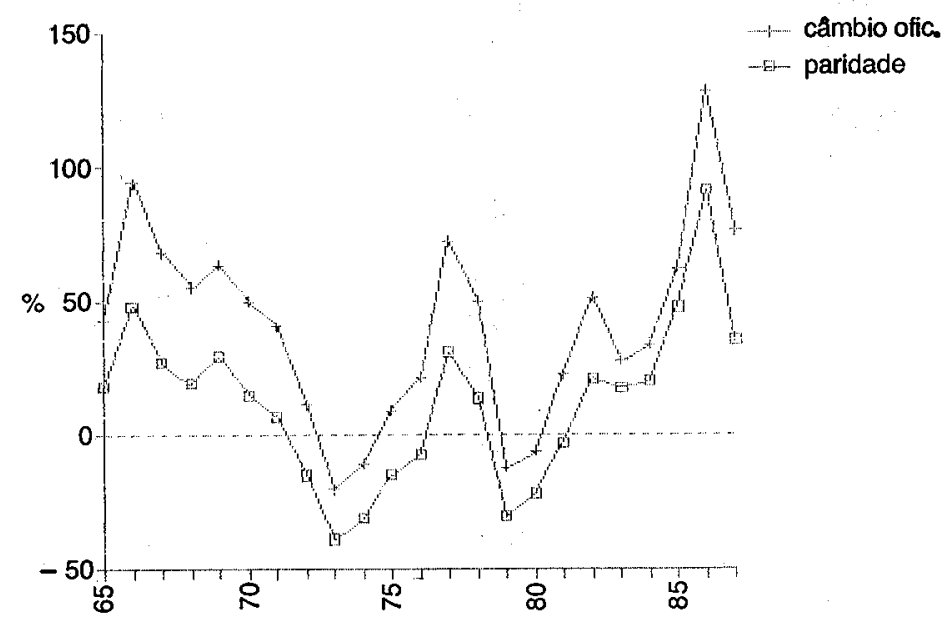




\section{GRÁFICO 2}

PROTEÇÃO NOMINAL AO CONSUMO DE TRIGO NO BRASIL $1967-1985$

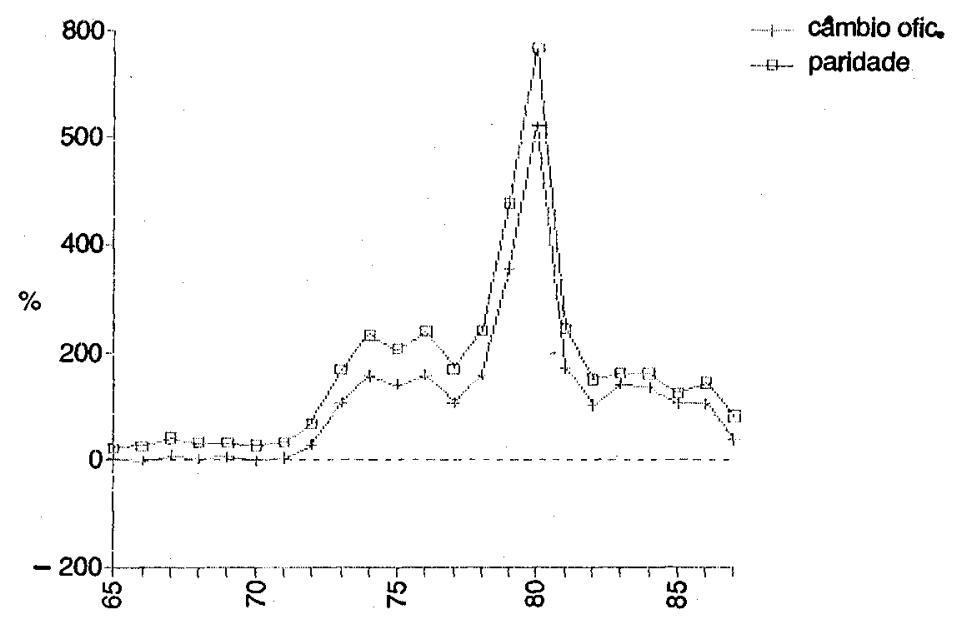

TABELA 2 - TAXA DE PRODUÇÃO NOMINAL À PRODUÇÃO TPNP - MÉDIA PARA ALGUNS SUBPERÍODOS; $1965 / 71-1982 / 87(\%)$

\begin{tabular}{ccc}
\hline Período & $\begin{array}{c}\text { Câmbio } \\
\text { Oficial }\end{array}$ & $\begin{array}{c}\text { Câmbio de } \\
\text { Paridade }\end{array}$ \\
\hline $1965 / 71$ & 59,11 & 23,52 \\
$1972 / 74$ & $-6,62$ & $-28,61$ \\
$1975 / 81$ & 22,49 & $-4,69$ \\
$1982 / 87$ & 63,28 & 38,80 \\
\hline
\end{tabular}

FONTE: tabela anterior 
Resumindo, houve subsídio de preço final (proteção nominal) ao trigo nacional entre 1965 e 1971; entre 1972 e 1981 houve uma "desproteção" ao produto e, a partir de 1982, o subsídio de preço final à produção doméstica se eleva, sendo o ápice em 1986, com 91\%, segundo a taxa de paridade (ver Tabela 1).

A produção nominal, aqui analisada, deve ser vista numa perspectiva de custos de oportunidade social, ou seja, se é mais vantajoso produzir trigo nacional ou importar, em se tratando de um país pequeno no comércio internacional do produto, em termos estáticos.

No entanto, a comparação entre preços domésticos e preços internacionais deve ser qualificada na avaliação da política, pois, como ficou claro anteriormente, a análise de proteção nominal é apenas indicativa, pois não incorpora ineficiências no mercado de insumos.

Farina et alii (1988) estimaram a proteção efetiva para o trigo em grão doméstico, para 1985, 1986 e 1987 que, conforme o Gráfico 1 , foram os anos de maior proteção nominal positiva no perílodo recente. $O$ estudo apresenta os resultados segundo quatro metodologias diversas:

a) utilizando apenas dois insumos - NPK e uréia, uma vez que os demais insumos não apresentam preços internacionais disponiveis; utiliza-se taxa cambial oficial;

b) utilizando, além dos insumos anteriores, todos os outros, obtidos por resíduo das informaçōes de custos agrícolas fornecidas pelo DERAL/PR, e considerando-os como sujeitos à alfquota zero (método de Balassa para tratamento de insumos não-comercializáveis). Os resultados são apresentados para taxa de câmbio oficial;

c) similar ao primeiro, porém utilizando-se uma taxa de câmbio de paridade com base em março de 1983;

d) similar ao segundo, com taxa cambial de paridade, com base em março de 1983.

A proteção efetiva foi, então, calculada pela fórmula abaixo, considerando-se os preços de livre-comércio do produto final e insumos intermediários na fronteira, i. e., preços CIF, eliminando-se da análise, deste modo, a proteção natural dada pelo custo de transporte internacional. A proteção efetiva transcrita logo abaixo, diz respeito à proteção não-tarifária da indústria doméstica de fertilizantes, uma vez que a proteção tarifária é desprezível: 


$$
g_{i}=\frac{\frac{P_{i} / E}{P_{i}^{*}}-\operatorname{SUM} a_{i j}{ }^{*} \frac{P_{i} / E}{P_{i}^{*}}}{1-\operatorname{SUM} a_{i j}{ }^{*}}
$$

Onde:

$\mathrm{g}_{\mathrm{i}}=$ proteção efetiva

$P_{i} \quad=$ preço do trigo doméstico

$\mathrm{P}_{\mathrm{i}}^{*}=$ preço $\mathrm{CIF}$ do trigo em livre-comércio

$a_{i j}{ }^{*}=$ coeficiente técnico de produção do insumo $\mathrm{j}$ na produção do bem $\mathrm{i}$

$P_{\mathrm{j}} \quad=$ preço doméstico do insumo $\mathrm{j}$

$\mathrm{P}_{\mathrm{j}}^{*} \quad=$ preço $\mathrm{CIF}$ do insumo $\mathrm{j}$ em livre-comércio

$\mathrm{E} \quad=$ taxa cambial

SUM $=$ somatório

Os resultados da Tabela 3 , abaixo, dizem respeito à comparação com EUA e Canadá, principais fornecedores mundiais do grão.

Verifica-se uma pequena proteção, no máximo $3,8 \%$ segundo a metodologia $\mathrm{D}$, em relação ao produto americano, em 1985 e "desproteção efetiva" entre 1986 e 1987, tanto na comparação com o produto americano ou canadense, indicando que não há uma política global coerente para o trigo ern grão nos anos analisados pela taxa de proteção efetiva, ou seja, ao mesmo tempo que se procura proteger o grão doméstico através de uma política de preços elevados, a proteção é eliminada devido à proteção à indústria de fertilizantes, cuja produção doméstica é ineficiente. No caso dos anos anteriores, em que a proteção nominal é menor do que entre 1985/87 ou negativa, tudo indica que a "desproteção" foi maior ainda, pois seria necessário um nível muito elevado de subsídio aos insumos, que não ocorreu, para contrabalançar o efeito da "desproteção" ao preço do produto final.

Portanto, são incorretas as afirmaçōes que atribuem ao Brasil uma nítida desvantagem comparativa na produção de trigo em grão, pois, apesar da baixa produtividade do cereal doméstico, observou-se, também, uma elevada ineficiência na produção doméstica de fertilizantes, cujos preços relativamente elevados em relação ao mercado inter- 


\section{TABELA 3 - TAXA DE PROTEÇÃO EFETIVA AO TRIGO EM GRÃO BRASILEIRO EM RELAÇÃO AO PRODUTO DOS EUA E CANADÁ; 1985/87 (\%)}

\begin{tabular}{|c|c|c|c|c|c|c|c|c|}
\hline \multirow{3}{*}{ ANO } & \multicolumn{2}{|c|}{ em relaçáo a: } & \multicolumn{2}{|c|}{ EUA } & \multicolumn{4}{|c|}{ CANADÁ } \\
\hline & & & & METOI & LOGIAS & & & \\
\hline & A & B & C & D & A & B & C & D \\
\hline 1985 & 1,068 & 1,739 & $1 ; 260$ & 3,828 & 1,171 & $-8,058$ & 0,363 & $-5,940$ \\
\hline 1986 & $-0,285$ & $-5,201$ & 0,269 & $-2,513$ & $-0,913$ & $-8,236$ & $-0,359$ & $-5,533$ \\
\hline 1987 & $-1,673$ & $-10,432$ & $-1,330$ & $-5,851$ & $-2,240$ & $-12,858$ & $-1,897$ & $-8,262$ \\
\hline
\end{tabular}

FONTE: Farina et alii, Impacto da Retirada do Subsidio ao Trigo Sobre o Consumo o Produçăo Nacionais, (1988).

A - Apenas uréia e NPK; taxa de câmbio oficial;

B - Inclui insumos não-comercializáveis com aliquota zero (método de Balassa); taxa de câmbio oficial;

C - Apenas uréia e NPK; taxa de câmbio de paridade;

D - Inciui insumos não-comercializáveis com alfquota zero (método de Balassa); taxa de cåmbio de paridade.

nacional, absorve a proteção de preço ao grão. Assim, nenhuma proposta de desregulação será razoável se nậo contemplar o aspecto da produção ineficiente de insumos utilizados na produção de trigo.

\subsection{Proteção ao consumo doméstico}

Para verificar como os consumidores foram beneficiados pela política de subsídio ao consumo, será usada a Taxa de Proteção Nominal ao Consumo (TPNC), tanto em termos de taxa cambial oficial como social ou de paridade:

$$
\text { TPNC }=\left(P_{w}-P_{c}\right) / P_{c} \times 100
$$

Nesta análise, $\mathrm{P}_{\mathrm{W}}$ é o preço $\mathrm{FOB}$ do trigo importado (acrescido das despesas de movimentação $\left.m_{b}\right), P_{c}$ é o preço de venda aośs moinhos. Os resultados anuais podem ser vistos pela Tabela 4 e Gráfico 2.

O Gráfico 2 mostra que, em termos da taxa oficial, entre 1965 e 
1971, não houve subsildio ao consumo. A partir de 1972, o subsídio ao consumo torna-se significativo, atingindo o pico em 1980, na verdade, um ano em que o subsídio ao consumo foi muito mais elevado do que a média. A partir de 1980, a TPNC 0 declina, mas o subsídio ao consumo manteve-se ainda em nivel elevado.

Observa-se que a taxa de subsídio de preço ao consumo foi uma política constante entre 1972 e 1987, ao contrário da política relativa à produção, que oscilou ao longo do perlodo analisado.

\begin{tabular}{lrc} 
TABELA 4 - TAXA DE PROTEÇÃO NOMINAL AO CONSUMO - & \\
\hline & TNPC; 1965/87 (\%) & \\
\cline { 2 - 3 } Ano & $\begin{array}{c}\text { Câmbio } \\
\text { Oficial }\end{array}$ & $\begin{array}{c}\text { Câmbio de } \\
\text { Paridade }\end{array}$ \\
\hline 1965 & 0,81 & 21,68 \\
1966 & $-4,12$ & 25,47 \\
1967 & 6,63 & 40,84 \\
1968 & 1,04 & 31,43 \\
1969 & 4,24 & 31,58 \\
1970 & $-2,73$ & 27,00 \\
1971 & 1,72 & 33,13 \\
1972 & 27,85 & 68,22 \\
1973 & 105,52 & 168,84 \\
1974 & 156,96 & 233,61 \\
1975 & 140,75 & 208,41 \\
1976 & 158,79 & 239,06 \\
1977 & 104,91 & 169,97 \\
1978 & 157,85 & 239,60 \\
1979 & 355,36 & 476,22 \\
1980 & 618,66 & 765,38 \\
1981 & 171,19 & 242,67 \\
1982 & 100,52 & 150,61 \\
1983 & 140,33 & 161,39 \\
1984 & 134,50 & 160,49 \\
1985 & 104,59 & 124,33 \\
1986 & 103,22 & 143,09 \\
1987 & 37,59 & 79,58 \\
\hline
\end{tabular}

Fonte: Silva (1989) 
A Tabela 5 apresenta os principais subperlodos, agregados conforme o tópico anterior. Verifica-se que, em termos de taxa cambial oficial, o perilodo 1965/7.1 apresenta uma proteçảo nominal ao consumo desprezível. Porém, em termos da paridade, o subsídio é da ordem de $30 \%$, ou seja, já nesse período, há um incentivo, embora não expljcito para o consumo de trigo através da redução do custo de importação.

No período seguinte (1972/74), como resultado da não-internalização da alta de preços internacionais, o subsídio ao consumo, medido pela taxa de proteção nominal ao consumo, com taxa de câmbio oficial, chega a $97 \%$, enquanto que, com a taxa de paridade, o subsidio atinge $157 \%$.

Entre 1975 e 1981, correspondendo à volta dos preços reais do mercado internacional ao nível pré-1972, destaca-se a política ativa de subsidio ao consumo. Se este for medido pela TPNC 0 , situava-se em tomo de $244 \%$. Se se levar em conta a sobrevalorização cambial do perflodo, o subsídio ao consumo atinge $334 \%$. Deste modo, conclui-se que, passado o choque de preços no mercado internacional, a política de subsídio ao consumo permaneceu, atingindo proporçōes muito maiores do que no perilodo do choque propriamente dito.

\section{TABELA 5 - TAXA DE PROTEÇÃO NOMINAL AO CONSUMO - TPNC - MÉDIA PARA ALGUNS SUBPERIODOS, 1965/71 - 1982/87 (\%)}

Anos

Cấmbio

Paridade

Oficial

$1965 / 71$

$1972 / 74$

$1975 / 81$

$1982 / 87$

1,08
96,78
243,93
103,46

30,16

156,89

334,47

136,58

Fonte: tabela anterior.

A partir de 1980, auge do subsidio ao setor triticola, o governo inicia uma programação de sua retirada gradual. Originalmente, previase o fim do subsídio até 1982, mas isto não ocorreu. Entre 1982 e 
1987, perílodo de redução abrupta da entrada de poupança financeira externa no pals, ocorre o ajuste interno da economia, verificando-se o inlcio da discussão sobre a retirada do subsldio ao consumo de trigo. A partir de 1983, a retirada do subsídio foi uma das exigências do FMI em relação ao ajuste interno da economia, gerando uma redução do nivel do subsídio ao consumo, mas não sua extinção, que só ocorre com o Plano Bresser em junho de 1987. Em termos de taxa oficial de câmbio, a proteção situa-se em 103\% entre 1981 e 1987, enquanto em termos de paridade, chega a $137 \%$, valores bem inferiores ao subperlodo 1975/81, porém, bastante elevados.

Portanto, ao contrário da política de preços para o triticultor, a política de preços para o consumidor de derivados de trigo foi sistemática entre 1965/87. O Gráfico 3 mostra a evolução da política para produtores e consumidores, indicando a ênfase no subsídio ao consumo.

\section{AS MUDANÇAS NOS HÁBITOS ALIMENTARES DA POPULA- ÇÃO DE SÃo PAULO}

Em termos absolutos, i.e., em relação ao consumo per capita, pelo Gráfico 4, percebe-se que foi nas classes de renda baixa e média (até 14 salários mínimos) que o consumo diário de equivalente em farinha aumentou. Nas classes de maior renda, não parece ter havido alteração no consumo, embora o número de observações dessas classes seja reduzido na amostra, não permitindo conclusões muito acuradas. $^{12}$

Através da Lei de Engel, que indica que há uma tendência à diversificação do consumo em direção a produtos mais sofisticados à medida que a renda se eleva, pode-se inferir que é muito mais provável a substituição de outros alimentos por derivados de trigo do que o contrário, tendência reforçada pela prolongada alteração de preços relativos entre os derivados de trigo e demais alimentos em função do subsídio ao consumo.

Conclui-se, então, que o efeito-renda do subsídio de preço ao consumo foi notável nas classes de menor renda, onde as despesas de alimentação são mais pesadas - cerca de $59 \%$ na classe de menor

12 Para um exame detalhado das informaçőes referentes a consumo per capita familiar e gastos das familias com derivados, ver Silva (1989). 
renda, caindo para $15 \%$ na de maior renda em 1971/72. Isto significa que, com a redução do preço dos derivados de trigo, houve uma liberação de renda proporcionalmente maior para as classes que originalmente dispendiam mais com esse produto, gerando, por parte delas, uma ampliação de consumo em geral e dos produtos de trigo, em particular. ${ }^{13}$

\section{GRÁFICO 3 \\ PROTEÇĀO NOMINAL AO TRIGO NO BRASIL 1967 - 1985 (paridade)}

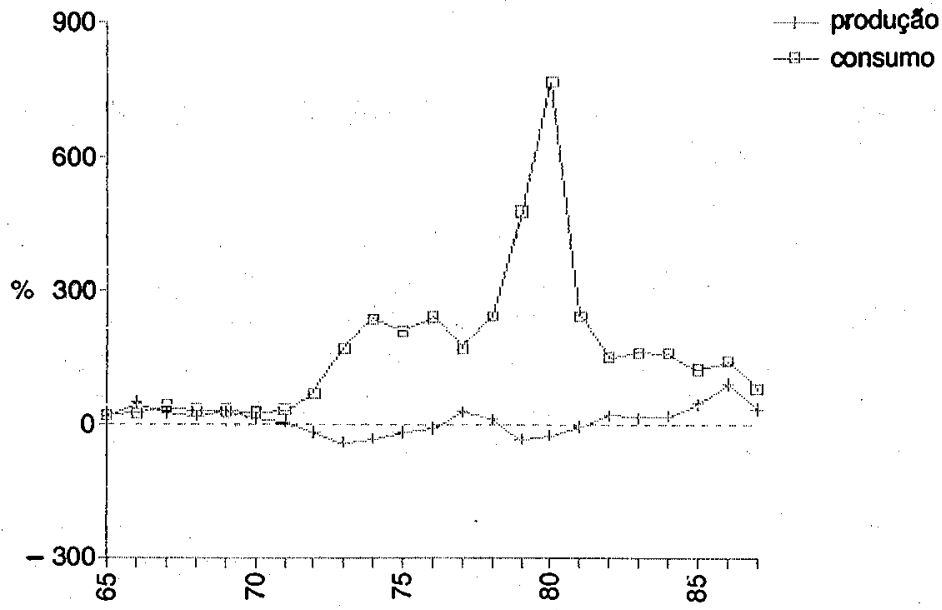

13 Soares (1980), cap. 4, chamara atençăo para o efeito-renda do subsfdio geral para o caso de um consumidor padrăo. A anállse aqui desenvolvida permite concluir que o efeito-renda $e$ multo mais importante para as classes de baixa renda, o que é corroborado por Campino et alii (1986) no que se refere às elasticidades-renda da demanda de farinha de trigo, por classe de dispendio, segundo as regiठes do ENDEF 1974/75. Segundo este trabalho, na regiáo II, correspondente a Săo Paulo, a elasticidade-renda da demanda de farinha de trigo representa 1,3623 para a classe de menor renda, caindo para $-0,3903$ para a classe de maior renda. 


\section{GRÁFICO 4}

CONSUMO PER CAPITA DE EQUIVALENTE

EM FARINHA - MUNICÍPIO DE SÄO PAULO

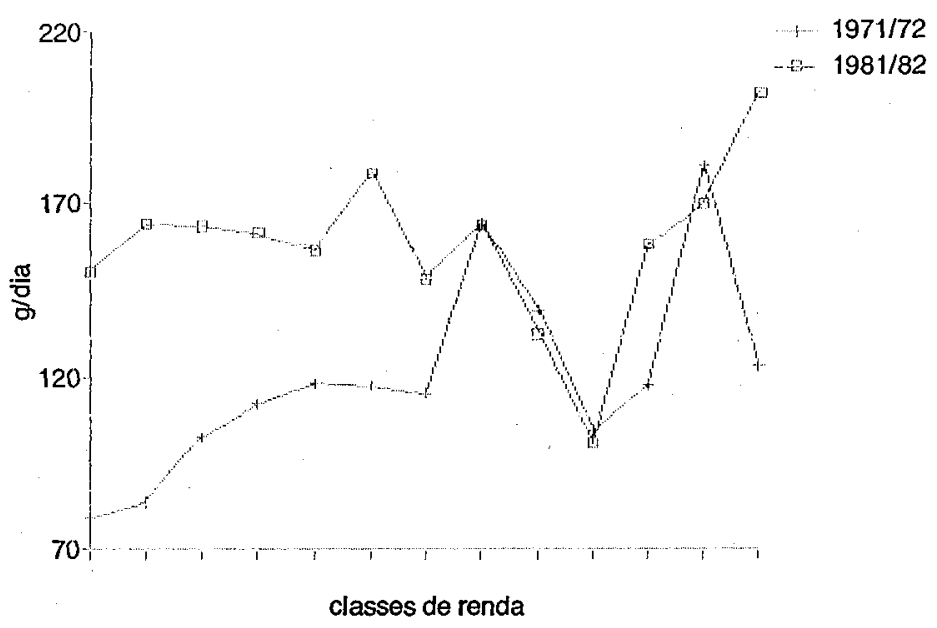

Obviamente, existe o fenômeno da absorçāo do subsídio ao consumo por famílias nos extratos superiores de renda. Porém, como ficou demonstrado pela análise da mudança nos hábitos alimentares por classe de renda familiar, e, ao contrário das análises difundidas sobre a questão, nāo foram as classes de maior renda que absorveram o grosso do subsídio ao consumo de trigo.

Se adicionarmos a isto o fato de que o subsídio ao consumo foi financiado por empréstimos externos, com prazos de carência e pagamentos extremamente vantajosos, concluiu-se que o subsídio ao consumo foi benéfico em termos sociais no curto prazo, i.e., possibilitou 0 consumo de alimentos a preços reduzidos. A longo prazo, a política pode ser nociva ao consumidor, dependendo da evolução da política global para o setor tritícola.

Como resultado do subsídio ao consumo de trigo, houve umá homogeinização do consumo dos derivados para todas as classes de renda ao nivel de consumo das classes acima de 14 salários mínimos, 
como conseqüência da ampliação do consumo por parte das classes de renda baixa e média. Este resultado foi observado especificamente para o município de São Paulo.

\section{CONCLUSÃO}

A polltica do trigo beneficiou o consumidor de derivados entre 1965/84. A partir de então, passou a priorizar o produtor do grão doméstico. A proteção nominal observada entre 1985/87 foi absorvida pela indústria de fertilizantes, que também é protegida internamente e que representa cerca de $30 \%$ dos custos de produção do trigo.

No que se refere à mudança nos hábitos alimentares da população, observou-se um forte crescimento do consumo per capita dos derivados de trigo por parte da população de renda baixa e média do município de São Paulo, que igualou o consumo per capita médio da população de alta renda, levando a crer que a política foi socialmente benéfica.

\section{BIBLIOGRAFIA}

CALEGAR, G.M. \& SCHUH, E. Costs, Benefits and Food Cunsumption Impact of the Brazilian Wheat Price Policy. Washington, D.C., International Food Policy Research Institute, 1986.

CAMPINO, A.C.C. et alii. A Questão Alimentar no Curto-Prazo: um Desafio Para a Política Econômica. São Paulo, FIPE/SEPLAN, 1986. (Relatório de Pesquisa não publicado, v. 2, p. 172.

CORDEN, W.M. The Theory of Protection. Oxford, Clarendon, 1971.

FARINA, E.M.M.Q., CYRILLO, D.C., CAMPINO, A.C.C. Impacto da Retirada do Subsidio ao Trigo Sobre o Consumo e Produção Nacionais. São Paulo, FIPE/INAN, 1988. (Relatório de pesquisa năo publicado).

KNIGHT, P.T. Substituição de Importação na Agricultura Brasileira: a Produção de Trigo no Rio Grande do Sul. Estudos Econômicos, São Paulo, 1(3): 71-101, 1971. Continuação: Uma Nota; 1(3): 115-7, 1971. 
Substituição de Importação na Agricultura Brasileira: à Produção de Trigo no Rio Grande do Sul: Resposta ao Comentário de A.R. Silva. Estudos Econômicos, São Paulo, 3(1): 162-6, jan./abr. 1973.

LABINI, P.S. Oligopólio e Progresso Técnico. Rio de Janeiro, Forense, 1980.

SILVA, A.R. Comentários Sobre o Trabalho: "Substituição de Importação na Agricultura Brasileira: a Produção de Trigo no Rio Grande do Sul". Estudos Econômicos, São Paulo, 3(1): 156-61, jan./abr. 1973.

SILVA, V.M. A Regulação do Mercado Brasileiro de Trigo: seus Beneficiários e Prováveis Conseqüências da Desregulação. São Paulo, 1989 (dissert. mestr. econ.), USP.

SOARES, R.P. Avaliação Econômica da Política Triticola de 1967 a 1977. Brasília, CFP, 1980. (Coleção Análise e Pesquisa, Vol.20).

TAVARES, M.C. et alii. Estrutura Industrial e Empresas Lideres. Rio de Janeiro, FINEP, 1978. 